\title{
Teorias do delito - modelo romano-germânico e de Common Law
}

\author{
Theory of crime - models Strafrechtswissenschaft and the Common Law
}

\author{
Tupinambá Pinto de AZEVEdo ${ }^{1}$ \\ Doutor em Direito do Estado e Teoria do Direito (UFRGS)
}

\begin{abstract}
RESUMO: A trajetória de um Direito Penal capaz de se tornar comum, supra ou internacional, dali irradiando um modelo ou sistema para os Estados-nacionais, talvez não se possa avistar no horizonte de nossos tempos. É possível fundir, unificar ou talvez harmonizar modelos de teoria do delito? A análise de questões básicas da Parte Geral, e também da Parte Especial, propõe ao pesquisador a inversão de seu ponto de visão: esse Direito Penal comum seria buscado, primeiro, nos sistemas regionais, ou comunitários, como a União Europeia ou a zona interamericana latina, talvez ibérica. Nada à vista do horizonte, mais uma vez, pois sequer se consegue uniformizar normas dentro de um mesmo território - como a surpreendente diferença que se encontra entre um Código Penal comum e um Código Penal Militar. A Parte Geral teria o dever de construir um sistema coerente e obediente a um Estado social e democrático de direito. Talvez por meio de uma espécie de Código Penal Central ou Lei de Introdução Penal, organizando princípios constitucionais pertinentes e regras flexíveis e pragmáticas eis a reserva de código. A grande caminhada empreendida convida a prosseguir, com a certeza de que não existem apenas obstáculos técnico-jurídicos e político-criminais a resolver, mas igualmente dificuldades de índole sócio-cultural.

Palavras-chave: Direito comparado. Microcomparações. Códigos penais tipo. Modelos de teoria do delito. Estatuto de Roma.
\end{abstract}

ABSTRACT: The trajectory of a Criminal Law capable of become common, international or supra, irradiating a model or system for Nation States, perhaps can not be sighted on the horizon of our times. The analysis of basic questions of the General Part, and also in the Special Part, proposes to the researcher a reversal of his point of view: this common Criminal Law would be pursued, first, in the regional or community systems, such as the European Union or the latin interamerican zone, maybe Iberian. Nothing on the horizon, again, because sometimes you can not even hamonize laws within the same territory - as the surprising difference between a ordinary Criminal Code and a military Criminal Code. The General Part would have a duty to build a coherent and obedient system to a social and democratic Rule of Law. Perhaps through some sort of Central Criminal Code or Criminal Introduction Law, organizing relevant constitutional principles and flexible and pragmatic rules - this is the reservation of code. The great walk undertaken invites to continue, with the certainty that there are not only technical-legal and political-criminal obstacles to solve, but also sociocultural difficulties.

Keywords: Comparative law. Microcomparisons. Theory of crime models. Model criminal codes. Rome statute.

1. A famosa obra de RENÉ DAVID, Os Grandes Sistemas do Direito Contemporâneo ${ }^{2}$, trazia direito comparado a partir de modelos, com três principais famílias - modelos do direito privado (que se caracterizaria como civil law), do direito comum inglês (common law) e os dos países socialistas. A queda do muro de Berlim, em 1989, exigiu importantes modificações nessa obra comparatista, embora ainda seja adotada por alguns autores. Recentemente, RICHARD VOGLER qualificou de subdesenvolvidas, e também estéreis, essas comparações de sistemas por meio de modelos. Indo além, afirmou limitada a análise textual e evidente o etnocentrismo das análises comparativas ${ }^{3}$. Propôs três metodologias que refletem tendências ou tipos ideais, vinculando instituições e ideologias históricas que lhes dariam sustento. Os paradigmas trazidos por VOGLER seriam: 1) o comunitário ou orgânico-familiar (Gemeinschaft); 2) o socializado (Gesellschaft), e 3) o autoritário (administrativoburocrático). Como o autor está fazendo comparação no âmbito das instituições processuais, afirma que essas instituições se caracterizam, no quadro proposto, como de justiça popular, adversarial e inquisitorial. Embora se encontre aí, uma divisão tripartida, pouco tem a ver com o sistema de três modelos, ao estilo de DAVID. É de notar, aliás, que no artigo referido aqui, de VOGLER, estão em liça sistemas acusatórios especificamente da Inglaterra e da Europa Central. 
Estudando essa temática, sob o ângulo dos sistemas penais, EDMUNDO HENDLER ${ }^{4}$ dá maior atenção a MAX RHEINSTEIN, que editou o IV volume, sobre Persons and Family, da Enciclopédia Internacional de Direito Comparado (abreviatura IECL). Versa a enciclopédia sobre direito comparado com 17 volumes, e particular ênfase na área do direito privado, sob os auspícios da Associação Internacional de Ciência Legal, repartição da UNESCO. Curiosamente, RHEINSTEIN insiste nos três sistemas mais discutidos no século $\mathrm{XX}$ - civil law, common law e direito socialista, no entendimento de que, à exceção das tradições do direito de família e matérias afins, que têm marcado aspecto consuetudinário e cultural, não haveria, hoje, um só país cujo direito deixe de pertencer a um dos três elencados.

Esse autor destaca a distinção entre micro e macrocomparação. FERREIRA DE ALMEIDA ${ }^{5}$ fala sobre essas duas espécies. A macrocomparação realiza-se pela comparação entre sistemas jurídicos considerados na sua globalidade. Sistemas que devem ser vistos como conjuntos coerentes de normas e de instituições jurídicas, vigentes em relação a um dado espaço e/ou comunidade. Já a microcomparação seria a comparação entre institutos jurídicos afins, em ordens jurídicas diferentes. $\mathrm{O}$ autor designa por “[...]instituto jurídico um conjunto de normas, princípios, instituições e organizações de natureza jurídica que, numa dada ordem jurídica, possam ser tomadas unitariamente sob certa perspectiva ou critério" $"$. Assim, "O direito comparado pode ser definido de modo analítico como a disciplina que tem por objeto estabelecer sistematicamente semelhanças e diferenças entre sistemas jurídicos considerados na sua globalidade (macrocomparação) e entre institutos jurídicos afins em ordens jurídicas diferentes (microcomparação) [...] $\mathrm{O}$ direito comparado se distingue do simples estudo de direitos estrangeiros pela utilização do método comparativo e pela apresentação de conclusões (síntese comparativa)"?

Sob perspectiva macro, RHEINSTEIN diz que três âmbitos culturais teriam, quanto aos sistemas penais, destaque: China, Islã e Ocidente. É no último que encontraríamos polarizados dois sistemas penais desenvolvidos no lado ocidental, o direito comum inglês e o originado na tradição do direito romano-germânico. Obviamente, há certa seletividade na escolha de apenas três sistemas macro, mas é preciso entender que o colonialismo e o neocolonialismo sufocou muito do multicuturalismo, caso, por exemplo, da Índia, onde a legislação britânica, durante a colonização, teve marcada influência nas instituições jurídicas implantadas no correr do tempo, sendo de notar que os próceres da independência hindu - como GHANDI e JAWAHARLAL NEHRU - estudaram direito na Inglaterra, e sob inspiração das aulas assistidas, utilizaram-se fartamente das garantias processuais da common law, como é o caso do uso da desobediência civil que culminou com a quebra dos laços coloniais. O Japão, já em 1890, fizera reformas legais com base no sistema alemão, e após a II Guerra Mundial, sob o domínio norte-americano, outras reformas se fizeram, acentuando a ocidentalização do direito no Extremo Oriente. Aliás, HENDLER invoca novamente VOGLER, que localizou "surpreendente semelhança do modelo inquisitorial europeu do medievo com o vigente na China, até fins do século $\mathrm{XIX}^{8}$.

2. Na interface da microcomparação, ao tratarmos da ciência criminal, sobretudo agora, em que Cortes Penais Internacionais ad hoc foram substituídas por um Tribunal Penal Internacional permanente (a partir do Estatuto de Roma), mais do que nunca é compreensível a eleição dos direitos romano-germânico e de common law, como principais polos do direito comparado - que dizemos microcomparado por que ambos os sistemas provêm do macrossistema que é o Ocidente. Embora a matriz comum, há grande diferença no entorno cultural desses sistemas ${ }^{9}$. Também cabe destacar que, dentro de um mesmo sistema, as características dos ordenamentos jurídicos nacionais são variáveis, como se percebe nas grandes diferenças entre o que ocorre nos Estados Unidos e o que vige na Inglaterra, ou, ainda na órbita de common law, entre tais países e outros como a Índia e o Sudão ${ }^{10}$.

Parece indiscutível que o surgimento dos Estados modernos, com enfraquecimento do poder monárquico, aprofundou formas diversas de investigação: inquéritos realizados por funcionários públicos, sob inspiração do direito canônico proveniente das Inquisições, a deixar clara a razão do desenvolvimento do sistema inquisitivo na Europa ocidental ${ }^{11}$; e investigações populares, praticadas em território insular (a ilha da Inglaterra e os demais recantos bretões), originando o júri de acusação e, ao fim, o julgamento através de jurados, institucionalizado com a supremacia parlamentar a partir da revolução inglesa do século XVII ${ }^{12}$. É verdade que, em certo momento, com a ideia de povo no poder, da Revolução Francesa e, depois, a invasão napoleônica, facilitando o conhecimento de costumes e instituições de outras nações, também na Europa central teve início o júri, mas enquanto nos países anglo-saxões há o modelo clássico de julgamento por gente do povo, Alemanha, Itália e França acabaram adotando um sistema de tribunal misto, o escabinato (ou escabinado) e o assessorado, com leigos e juízes 
técnicos, integrando, portanto, tribunais de composição mista $^{13}$. As duas revoluções, a francesa e a inglesa, embora ambas sob o signo da queda ou redução de poderes da nobreza, com ascensão da burguesia, acentuaram caracteres distintos: NAPOLEÃO introduz a codificação, e os advogados ingleses, "enquanto lutavam para transformar comerciantes em clientes, [...] lançaram uma campanha [...] contra todas as instituições judiciárias não incluídas no âmbito das cortes de direito costumeiro"14. O combate ao sistema inquisitivo teve apoio na Magna Carta, e suas garantias individuais, com base na lei da terra. O devido processo legal, criação inglesa, interrompe o sistema inteiramente inquisitivo, e dá alento ao júri - de início, com poderes de investigação, e adiante, não mais instituído para conhecer os fatos, mas informar-se sobre eles e julgar ${ }^{15}$.Um sistema novo de rito processual, que afastava as práticas ex officio: juramento feito pelo réu, levando à autoincriminação, proibição de reperguntas. Emerge, com mais força, o habeas corpus.

O caso brasileiro merece atenção, pois estabelecemos Códigos Penais e Processuais Penais à base do modelo romano-germânico, mas acabamos por institucionalizar um júri, com influência inglesa, embora o sistema cartesiano de quesitos fosse claramente inspirado no sistema francês (mas sem o escabinado). Há bem pouco tempo, na reforma processual penal de 2008 (L. 11.689), aproximamo-nos um pouco mais do sistema anglo-americano, através de um quesito reducionista sobre absolvição (art. 483, Inciso III, CPP).

Importa-nos, neste texto, a teoria do delito, reservando-nos para outra ocasião o estudo do processo penal. $\mathrm{O}$ rápido esboço sobre este último permitiu destacar alguns contrastes de microcomparação, úteis para o estudo dos dois sistemas penais desenvolvidos na Europa, com tanta influência nos demais continentes.

3. Temos códigos penais desde a Independência brasileira, em seguimento às Ordenações, estas, sem a sistematização de um código, mas já com a preponderância da lei escrita, em prejuízo do precedente. Filiamo-nos à civil law. Na linha do tempo, a partir do Código Penal de 1890, temos: a Consolidação das Leis Penais (1932) e o Código Penal de 1940. Todos, no modelo napoleônico de Parte Geral e Parte Especial. Tivemos, no Brasil um Código Penal sancionado em outubro de 1969, mas que ficou com vigência suspensa, até 1974, quando revogado; o que significa dizer que nunca entrou em vigor. Em 1984, toda a Parte Geral foi modificada, e a Parte Especial somente vem recebendo alterações casuísticas no decorrer dos anos. São os diplomas de que dispomos, revisados, atualizados, e às vezes mutilados por ofensa a princípios da Parte Geral, ou da própria Constituição. Há também o Código Penal Militar, de 1969, atualmente em vigor (o Código anterior era de 1944). Todos os códigos referidos aqui, do século $\mathrm{XX}$, foram promulgados em períodos ditatoriais, ou seja, através de Decretos-Leis, estando em recesso o Congresso Nacional - 1940, 1944, 1969 e $1984 \ldots$

A dogmática penal, "sistema de conceitos construído para descrever o ser do Direito Penal", tem como aspecto angular a teoria do fato punivel ${ }^{16}$. Diz-se que a definição analítica do delito, ou seja, do fato punível, perfeitamente identificável em nossos códigos penais, leva ao desdobramento de três categorias: conduta típica, ilícita e culpáve ${ }^{17}$. Muitos doutrinadores preferem uma duplicidade: tipo de injusto e culpabilidade ${ }^{18}$. Afastado estaria o sistema tripartido, pela contração entre tipo legal e de ilicitude. Didaticamente, a maioria adota o sistema tripartido. As divergências são pontuais: BASILEU GARCIA era talvez o único a seguir a trilha de NELSON HUNGRIA, acrescentando como elemento a punibilidade - em verdade, consequência do crime, e não elemento definitório deste ${ }^{19}$. Também divergente, RENÉ DOTTI, sustentando opinião pessoal no sentido de que "o delito se aperfeiçoa com a ação típica e ilícita e que a culpabilidade, como juízo de reprovação post factum, é um elemento da pena. E no quadro da teoria geral da pena deve ser estudada" ${ }^{20}$.

O Código Penal de 1940, em seu texto original, tem clara influência da doutrina italiana, e em vários dispositivos estava inspirado no Código Rocco, de 1930, do fascismo mussoliniano. Todavia, não aceitou o positivismo criminológico, que ainda vicejava a essa época, embora dando ênfase, ao lado da culpabilidade, à periculosidade. Quando da reforma de 1984, a Parte Geral de nosso Código rendeu-se a influências germânicas, como está clara a admissão dos erros de tipo e de proibição, além de dispositivos que se aproximam da teoria finalista da ação, entre outras inovações ${ }^{21}$. Na segunda metade do século passado, até os tempos atuais, a teoria romano-germânica do delito poder-se-ia chamar de teoria germânica, pois as teses dos juspenalistas alemães têm profunda aceitação na Europa central e na América Latina ${ }^{22}$.

4. Embora o grande debate que surgiu a partir do Estatuto de Roma, em que a tipificação dos crimes internacionais se dá nos moldes da legalidade penal ao estilo da Strafrechtswissenschaft (nullum crimen,nulla poena sine lege scripta, praevia, stricta, certa), há muito se afirma crescente aproximação entre a teoria do delito romano-germânica e da common $L_{a w}{ }^{23}$. 
JEAN PIERRE MATUS faz aprofundado estudo da comparação entre os dois sistemas teóricos, destacando a distinção entre justificativas e exculpantes, do sistema germânico, e a indiferenciação de ambas, como defenses, na Common Law, e a afirmada perda de sentido dessa distinção, nos sistemas holísticos hoje em voga ${ }^{24}$. É interessante notar que, nas Cortes Internacionais ad hoc, a partir de Nuremberg e de Tóquio, sempre houve predomínio da teoria angloamericana. Mas, embora representantes dos Estados Unidos tenham participado da criação do Estatuto de Roma, a ausência norte-americana no Tribunal Penal Internacional facilita a predominância do sistema europeu continental. MATUS examina detidamente a jurisprudência dos Tribunais ad hoc, onde é clara a influência e até imposição dos Estados Unidos, na criação de tais jurisdições e atuação nelas, e o caráter majoritário dos representantes da tradição romanogermânica, sobretudo esta, funcionando magistrados e assessores no Tribunal Penal Internacional permanente. Mas, adverte, não se percebe relação causal entre o tipo de procedimento (adversarial ou inquisitivo) e a teoria do delito efetivamente adotada ${ }^{25}$. Sob o ângulo procedimental, no direito internacional penal afasta-se a hipótese do júri, atuando câmaras ou sessões com juízes técnicos, togados.

É na teoria do delito que residem as dúvidas. Tomemos um exemplo: o debate sobre culpa/ culpabilidade no Estatuto de Roma. Estaria, ali, culpa como elemento do tipo, tal como ocorria, entre nós, com a teoria causal, ou a intenção, culpa ou dolo, trasladaramse para a culpabilidade, e são elementos desta, aceita a teoria finalista? Onde localizar a mens rea, do sistema anglo-americano? MELENDO PARDOS traz à colação o magistério de ALBIN ESER 26: "quando se lê sobre o elemento mental alguém pode, talvez, esperar mais que uma mera regulação da intenção e o conhecimento ou a exclusão da recklessness ${ }^{27}$ e a imprudência. A razão é que entendido elemento mental como mens rea, qual aparece nos projetos do Estatuto de Roma (a frase latina se traslada ao inglês moderno, em termos de mente culpável, como ocorre comumente), a culpabilidade penal por crime internacional parece ser sinônima de intenção e conhecimento e, assim, fica restrita a um fato puramente psicológico. Outra possibilidade está em ver na culpabilidade um significado mais amplo, indo além da tipicidade, por requerer, além da intenção e o conhecimento, alguma classe de culpabilidade normativa ou reprovabilidade, que pode faltar se o agente, como nos casos de enfermidade mental ou estado de necessidade exculpante mata a um ser humano, com intenção do resultado ou assunção do risco, e será inimputável. Esse conceito amplo aparece em códigos como o austríaco e alemão, que expressamente falam de culpabilidade ou reprovabilidade em termos distintos da intenção e da imprudência, de modo que, de fato, reconhecem tanto elementos psicológicos, reunidos todos sob a designação comum de elementos subjetivos. Pelo contrário, o Estatuto de Roma parece aderir ao conceito de elemento mental psicológico mais estrito (intenção e conhecimento de acordo com o art. 30), enquanto a incapacidade do acusado para apreciar o ilícito de sua conduta ou sua atuação sob coação se descrevem, menos especificamente, como causas de exclusão da responsabilidade penal. Para ele (ESER), esta aproximação mais psicológica, antes que uma censura normativa, pode explicar por que o erro de direito excluirá a responsabilidade penal somente se negar o elemento mental - art. 32 (2) -, diferentemente do que ocorre na Alemanha. Assim, dificilmente podese acreditar numa plena compreensão da culpabilidade no Estatuto, como ocorre em algumas ocasiões ${ }^{28}$.

Contudo, o próprio ESER destaca que Códigos, como o francês e o espanhol, nem falam especificamente em elemento mental, nem distinguem a falta de culpabilidade de outras causas de exclusão de responsabilidade, o que não impediu à doutrina desses países de desenvolverem conceitos normativos de culpabilidade. Conclui que é possível um desenvolvimento semelhante de um conceito mais amplo do elemento mental, sendo considerada a culpabilidade normalmente, no Estatuto de Roma ${ }^{29}$. Mas a jurisprudência da Corte não confirma tal previsão, pois ESER está focado exclusivamente em interpretação originada na dogmática alemã. MELENDO PARDOS demonstra que, se o elemento mental está presente nos elementos materiais, na linha de ESER, e estes são encontráveis na definição do crime, a conclusão é que só o erro de direito, que afete a um elemento material dessa definição, poderá excluir alguém de responsabilidade, pois só este será capaz de eliminar o elemento mental. Talvez a solução esteja em uma interpretação alternativa, mas MELENDO adverte: a interpretação alternativa tem, aparentemente, seu preço - o dolus malus ${ }^{30}$.

São pequenas amostras das dificuldades decorrentes da necessidade de construir uma dogmática híbrida, que tenta combinar institutos jurídicos ainda não aptos para tal unificação. Note-se que o Estatuto ainda mantém a antinomia erro de direito e erro de fato, enquanto a doutrina da criminal law europeia, há muito, lida com erro de tipo e erro de proibição. Para nós, o dolus malus está suplantado pela consideração do dolo normativo. Enfim, em nossa cultura jurídica acolhemos o mala prohibita, pedra angular de nosso princípio da legalidade penal, enquanto em common 
law, seara dos precedentes, o modelo consuetudinário se socorre, ainda, do mala in $s^{31}$.

A importância desta comparação tem, entre outras razões, a necessidade indiscutível de ser encontrada uma dimensão comum, um denominador que aproxime sistemas, modelos ou famílias jurídicas, pois se trata de jurisdição global(izada).

5. Mas quando nos valemos desse argumento, para a tentativa de fusões, unificações ou harmonizações jurídicas também em sede continental ou regional, por vezes surgem dificuldades como as decorrentes do multiculturalismo, de rivalidades fronteiriças e até de conflitos que a história de cada povo registra e, pela tradição, realimenta, à base da chamada memória histórica coletiva ${ }^{32}$, seguidamente meras memórias inventadas ${ }^{33}$.

Antes de comentarmos o projeto do Código Penal Tipo para a América Latina, uma referência à União Europeia, tendo como guia JOHN VERVAELE, em trabalho que analisa o desenvolvimento do Direito Penal na integração europeia ${ }^{34}$. Segundo o autor, seria preciso partir das ideias de cooperação e harmonização, e como professor na Faculdade de Direito de Utrecht, propôs confrontar a posição holandesa com a dos demais países europeus. Uma pesquisa centralizada no estudo da decisão do Tribunal Europeu de Justiça no processo C-173/03. Ocorre que, no processo C-176/031, o Tribunal de Justiça Europeu afirmou sua competência para harmonizar sanções penais em crimes ambientais. Ou seja, o Direito Penal teria um papel supraconstitucional, acima das soberanias nacionais, na área ambiental. Não é âmbito tão reduzido, como poderia parecer à primeira vista, pois questões ambientais adentrariam questões tipicamente holandesas, nas palavras de políticos e acadêmicos dos Países Baixos, tais como drogas, aborto e eutanásia. Uniformização, harmonização, cooperação, são sempre sensíveis quando se trata de direito punitivo, tendo como sede geradora da normatização organismo(s) situados além fronteira. Mais uma vez, por exemplo, a Assembleia Nacional francesa ressuscitou o espantalho do governo de juízes, acima de políticos e parlamentos. Com o Tratado de Maastricht, muito se falou sobre uma continentalização ou europeização do Direito Penal, colocado, à época, no que se chamava terceiro pilar da União. Por que tanto receio de harmonização do Direito Penal? Seria melhor manter um sistema de precedentes judiciais, sem substituí-lo por Diretivas?

Vale ressaltar que apenas os Países Baixos se posicionaram, no caso em tela, deixando espaço para a harmonização da legislação penal, mas sem abrir mão de diferenças culturais na legislação nacional, relativas ao Direito Criminal, e de tradicionais princípios, bem como intocado o devido processo legal. Alguns progressos haviam ocorrido, a partir de Maastricht, quanto a sanções penais, mas sempre em meio a controvérsias. Em 1990, a Alemanha considerou já ultrapassados os limites do Tratado, tornando expresso aquilo que muitos Estados tratavam com contrariedade, mas se mantiveram silentes, frente à dissidência alemã. Ao fim, no que se registrou como caso C-240/909, a Corte Europeia se declarou funcionalmente competente para harmonizar sanções punitivas, com base nas garantias penais do artigo 6 da Convenção Europeia de Direitos do Homem (CEDH). Mas VERVAELE dirá, inclusive, que "quatorze anos após a decisão, não se podia dizer que a CE tivesse feito extenso uso desse poder" 35 .

$\mathrm{O}$ antigo terceiro pilar, a rigor, nunca obteve avanços, pois a Comissão Europeia e a EU sempre se colocaram em campos opostos, reduzindo drasticamente a decisões da CE. "A Comissão apresenta propostas para a harmonização do Direito Penal que o Conselho rejeita ou por elas não se apega. $\mathrm{Na}$ melhor das hipóteses, a proposta é neutralizada e despojada de seu conteúdo penal." Segundo VERVAELE, seria a velha tática legislativa que pode ser vista na regulamentação da Comissão, quanto à segurança alimentar (2003): a Comissão destaca a necessidade de uma harmonização funcional da lei penal, adicional à já existente harmonização administrativa, além da fixação de uma lista de infrações cometidas com dolo ou culpa grave, capazes de ameaçar segurança alimentar e saúde pública. Para isso, os Estados-membros devem prever sanções penais, com normas mínimas. Nada foi feito, nenhuma proposta de Decisão-Quadro apresentada, finalmente, no Conselho, despojaram a proposta da Comissão, de qualquer elemento de Direito Penal. Teriam razão tais países, pela insignificância das condutas a serem coibidas? Bem ao contrário, eram conhecidos "escândalos alimentares em muitos países europeus. Em alguns casos, como o triste caso do óleo de colza, na Espanha, que causou a morte de muitas pessoas." A conclusão demonstra que os EstadosMembros não parecem muito preocupados com aplicação de regras penais comunitárias, destacando VERVAELE que só há efetivo interesse em matéria de terrorismo, crime organizado, e pouco mais. $\mathrm{O}$ fracasso do Projeto Alternativo de Justiça Penal Europeia, no qual estavam empenhados grandes jusinternacionalistas, mostra claramente a dificuldade decorrente da sempre prestigiada soberania naciona $l^{36}$. Sem falarmos acerca da frustrada tentativa de uma Constituição Europeia... Nas considerações finais de seu texto, VERVAELE é veemente: "O Direito Penal reflete, sem dúvida, uma 
parte da cultura jurídica nacional e, portanto, é um símbolo da soberania do Estado. Ao desenvolver o modelo de integração europeia baseada na soberania partilhada é lógico que os Estados-membros devem cooperar na criação de uma cultura jurídica comum, também na área do Direito Penal.” Só será alcançado esse estágio, quando todos - Estados-Membros e União Europeia - apoiarem uma política criminal comum. O professor VERVAELE é enfático, ao sustentar que " $\mathrm{O}$ tema do debate já não é saber se queremos um Direito Penal europeu, senão para quê o queremos e sob quais condições". As tentativas de ampliar o espaço do direito penal não devem estar adstritos à segurança nacional criminal, mas na "previsão dos valores penais europeus".

6. Trazendo o foco para a América Latina, pouco acrescentaremos. De 1963 a 1971, os melhores criminalistas latino-americanos buscaram um Código Penal Tipo para a América Latina. No último ano mencionado, ocorreu, em São Paulo, a reunião plenária de aprovação final da Parte Geral ${ }^{37}$. Estávamos diante do que representa, nos códigos de direito material, princípios e regras fundamentais, no intento de plasmar um sistema de garantias - pois no caso específico do direito criminal, o escopo é sempre garantista. E mais: também o direito formal, ou seja, o Código de Processo, e não apenas em matéria penal, tem esse marcado viés garantista. A aplicação da norma inscrita no direito material passa, necessariamente, pelo direito processual. Sabidamente, Código de Processo é um livro de garantias constitucionais, como de resto, todo o direito processual é direito constitucional aplicado $^{38}$ - pois reproduz e desenvolve os grandes princípios-garantia elencados na Constituição. Seria irrealizável uma empresa voltada a um código de tipificações criminais, pois cada Estado-nação tem suas peculiaridades. Na América Latina, para nos fixarmos no projeto mencionado, há culturas diferenciadas, e mesmo em áreas urbanas, onde se imagina presente maior uniformidade de valores e respeito a crenças presentes na comunidade, existem as subculturas: o fenômeno recente da Polícia Pacificadora, nas favelas do Rio de Janeiro, busca levar o Estado a todos os munícipes, lá onde o Estado somente aparecia através de uma polícia não-pacificadora, revistando os moradores, derrubando portas, usando da força da lei. BUSTOS RAMÍREZ falava disso, ao cuidar da culpabilidade atribuída a quem está despido dos benefícios e valorações da gente do asfalto ${ }^{39}$. Nesse mesmo sentido, a co-culpabilidade, cunhada por ZAFFARONI. E a extraordinária monografia de BOAVENTURA DE S. SANTOS ${ }^{40}$, que discute o conceito de pluralismo jurídico, negando o monismo jurídico, a partir de uma favela a que atribuiu o nome metafórico de Pasárgada. Na América Latina, onde tantos sobreviventes dos indígenas habitam cidades e campos, muitos ainda reunidos em tribos, certamente conhecem e acreditam em normatividades que não são aquelas produzidas pelo Estado. Recentemente, em obra intitulada La Pachamama y el Humano, o Ministro ZAFFARONI traçou a genealogia de populações da Bolívia e Equador, que aparecem contempladas nas novas Constituições desses dois países andinos, afirmando que comunidades originárias dessa região vivenciam paradigma que não é o do nosso conhecido constitucionalismo liberal antropocentrista ${ }^{41}$. Em conotação diversa, mas considerada situação antropológica (?) capaz de levar o agente a praticar condutas, ignorando o sentido de proibições constantes de nosso Código Penal de 1940, o artigo 22 considerava irresponsáveis (inimputáveis) agentes que, por [...] "desenvolvimento mental incompleto ou retardado", eram, ao tempo da ação ou da omissão, inteiramente incapazes de entender o caráter criminoso do fato ou de determinar-se de acordo com esse entendimento; sendo semirresponsáveis os que, pela mesma condição, não possuíam a plena capacidade de entender o caráter criminoso do fato ou determinar-se de acordo com esse entendimento. NELSON HUNGRIA, redator do dispositivo legal, explicava que esse artigo 22, ao falar em "desenvolvimento mental incompleto ou retardado", incluía "até mesmo os silvícolas inadaptados". Adiante: "[...] não há dúvida que entre os deficientes mentais é de se incluir também o homo Sylvester, inteiramente desprovido das aquisições éticas do civilizado homo medius, que a lei penal declara responsável." Diante de críticas a esse trecho do dispositivo legal, que seria palavroso e redundante, pois de desenvolvimento incompleto já tratava o artigo 23 (menores de 18 anos), HUNGRIA argumentava que nessa rubrica do art. 23 não cabiam os silvícolas, e caso afastada a referência a desenvolvimento mental incompleto ou retardado" (interpretação extensiva permitiria aos deficitários congênitos do desenvolvimento psíquico, ou oligofrênicos, o enquadramento no 28), seria necessário dispositivo aludindo, expressamente aos silvícolas, com o que surgiriam suposições falsas, "no estrangeiro, que ainda somos um país infestado de gentio" (sic).

Logo a seguir retornaremos, brevemente, a essas questões multiculturais. Voltemos antes, à elaboração do Código Penal Tipo, pois é essencial anotar a razão pela qual não tiveram prosseguimento os trabalhos, após a reunião plenária de São Paulo. É que os estudos foram truncados em 1976, pela ingerência de assuntos 
políticos propiciados pelas ditaduras que imperavam na América Latina, e alguns dos membros da Comissão, pertencentes à Corte Suprema de Justiça da Colômbia, foram assassinados no próprio Palácio da Justiça! Indubitavelmente, não eram tempos propícios para projetar leis voltadas para o asseguramento de direitos fundamentais/humanos. Dezoito anos depois, em 1994, na X Conferencia de Ministros de Justiça dos Países Iberoamericanos, em Cartagena de Índias - Colômbia os trabalhos foram retomados, agora decidida a elaboração de um Código Penal Iberoamericano (portanto, com inclusão da Espanha, e com a possibilidade de inclusão de Portugal). Sucederam-se sete encontros da Comissão Redatora do Código Penal Tipo Iberoamericano (1995 Bogotá; 1996 - Las Palmas de Gran Canaria (Espanha; 1998 - Panamá; 2000 - Bogotá; 2002 - Costa Rica; e 2003 - Bogotá. Entre propostas aprovadas no curso das Comissões Redatoras cabe destacar a inclusão da responsabilidade penal da pessoa jurídica. Por outro lado, na reunião do México, em 2001, deu-se a criação do I Simposio Internacional de Política Criminal Legislativa, dedicado às "Orientaciones políticocriminales de la futura legislación penal en el ámbito iberoamericano" 42 .

Retomando, en passant, a situação das comunidades originárias da América, o Informe sobre os últimos trabalhosos da Comissão Redatora traz esta passagem:

(16) Um caso particular, mas comum sobretudo nos países andinos, é o das populações aborígenes e, em particular, aquelas que não estão integradas totalmente no sistema oficial. Além da previsão de uma norma relativa às condições da punibilidade (erro de proibição por razões culturais, por exemplo), é preciso meditar sobre se é conveniente submeter seus membros, que delinquem, a uma pena particular e se, de acordo com a índole da infração, aceitar a reação penal própria a suas comunidades ${ }^{43}$.

7. A tendência natural é enxergar como local, ou até regional, o crime em espécie. É certo que a descodificação ${ }^{44}$ não representou fenômeno apenas do direito penal, mas enquanto nas demais províncias da ciência jurídica e da política judiciária há um movimento de retorno - a recodificação-, sempre mais se produzem leis extravagantes, que fogem ao Código Penal. Leis especiais demonstram as peculiaridades de cada território. Ou, talvez, a fuga a um sistema que traz consigo valores, e a hipertrofia de normas penais traduzindo o discurso de legisladores despreparados para o entendimento das questões punitivas?

É grande o número de juristas clamando pela volta a um sistema de códigos centrais ${ }^{45}$, amedrontados diante dajudicialização da política e da politização do judicial, da indeterminação dos princípios constitucionais, e agora até assustados pela avassaladora movimentação do direito internacional - diante da proposta de uma nova pirâmide jurídica, em que a Grundnorm não mais estaria na Constituição, mas nos Tratados e Convenções de Direitos Humanos ${ }^{46}$.

BENETTI TIMM é defensor da recodificação, no espaço civil, pois o código "Poderá fornecer os guias para a manutenção da unidade própria do Direito Privado, mantendo intacta a história dos civilistas (ainda que sugerindo releituras e eventuais quebras de paradigmas na regulação de alguns institutos). Seu grau de vagueza semântica poderá ensejar interpretações contemporâneas daqueles institutos que compõem a estrutura do sistema capitalista em constante evolução. Nesse sentido, propriedade, contratos e responsabilidade civil, na era da sociedade em redes e da globalização, deverão ser reconstruídos dogmaticamente a partir do sólido pilar da legislação civil e não apenas em cima de vagos princípios constitucionais que foram concebidos em um momento muito particular da história política brasileira" 47 .

Entendemos que em persistindo vaguezas semânticas, esse código estará vulnerável à mesma crítica feita, seguidamente, aos vagos princípios constitucionais. Em termos penais nossa proposta é em prol da reserva de código: um texto específico sobre direitos e garantias individuais e sociais, de caráter penal, arejando as pautas do Supremo Tribunal Federal e, no sentir de DANIELPASTOR, “a legislação punitiva deve estar organizada sob a metodologia da codificação para assegurar também o conhecimento simples e seguro dos deveres penais por parte da população. Em outras palavras, o penal deve ser um direito acessivel não só para o púbico, mas também para os juristas, convertidos hoje, cada vez mais, em analfabetos funcionais pela impossibilidade de conhecer toda a legislação, o que não é um problema da especialização devido a que toda a legislação extra codicem, seja de parte geral ou não, termina determinando os contornos definitivos da verdadeira parte geral do direito penal sem que, portanto, saibam de onde vem a inspiração de certas soluções" ${ }^{48}$.

8. A busca de um Direito Penal mínimo parece longínqua, diante da chamada expansão punitiva ${ }^{49}$ : não se trata apenas da teoria do risco, dos crimes de perigo abstrato, da pretensão de dispensar, na tipificação, a presença de bem jurídico a ser protegido, do intento de fragilizar as garantias processuais penais, diante dos crimes de massa, transnacionais - e aí estão, dispostos a substituir o Direito Penal, o Direito Administrativo Sancionador ${ }^{50}$ e o Direito de Intervenção ${ }^{51}$, Substituição 
que, ao cabo, implicaria em deslocamento do primeiro, perdendo a condição de ultima ratio: se o combate à macrocriminalidade, v.g., se faria com desprezo a garantias individuais já consuetudinárias, por essas vias substitutivas do direito punitivo, afinal subscreveríamos a abolição do Direito Penal, lato sensu.

O Direito Penal, em sua linha de tempo, foi preferencialmente a arma dos mais fortes, na luta darwiniana para eliminação dos débeis ${ }^{52}$. Dois são os sentidos, contrapostos, que podem ser percebidos, na expressão direito penal mínimo: hoje, pensamos em menos tipificações, sanções penais que podem ser transacionadas, dando lugar a reparações ou outras alternativas descriminalizadoras; mas anteriormente, era mínimo pelo fato de que só deveria atingir as classes perigosas: mendigos, vadios, prostitutas, loucos de todo o gênero, hereges. A expansão, que se tornou lugar comum, decorreu, entre outras causas, do fim da família tradicional, do consumismo, do stress da vida contemporânea, da fuga para o mundo virtual e a droga, da baixa estima, da anomia. As fronteiras não se expandiram, mas foram ultrapassadas, e o crime organizado mostrou os caminhos para o transnacional. Também se inicia uma nova caça: contra os de colarinho branco (white colar crime). A corrupção, em todos os níveis, acompanha essas novas formas de viver. Os chamados crimes internacionais sempre existiram, mas passaram a ter nomes, definições, tipificações e até tribunais supranacionais.

Nesse contexto, o Estatuto de Roma, as propostas de Direito Penal tipo, para abranger comunidades regionais, reservam surpresas ao pesquisador: o Estatuto de Roma é menos voltado para princípiosgarantidores, e mais apto para obter adesões de Estados-nacionais a crimes em espécie: contra a humanidade, genocídio, de guerra, de agressão. O Tribunal Penal Internacional leva-nos à aceitação do direito penal do inimigo. Quem é levado para processo e julgamento permanece, durante toda a investigação e procedimento sob prisão preventiva, sem prazo de encerramento, e durante nas salas de audiências poderá estar o réu dentro de celas transparentes e à prova de balas, à disposição da mídia. É a época do voyeurismo absoluto. Não é difícil convencer um Estado-nação a promulgar seu próprio Código Penal Internacional, transposição do Estatuto de Roma para cada país. É o caso emblemático do Código Penal Internacional alemão, que entrou em vigor em 30 de junho de 2002, um dia antes da entrada em vigência do Estatuto de Roma, na Alemanha ${ }^{53}$, Em 25 de setembro de 2006, a República Oriental do Uruguai publicou a Lei 18.026, sob o título de Cooperación com la Corte Penal Internacional en matéria de lucha contra el genocídio, los crímenes de guerra y de lesa humanidade ${ }^{54}$. É importante cumprimento da promulgação, no cenário nacional, de Estados que aderem ao Estatuto de Roma. Para que se implemente a complementariedade entre norma nacional e internacional, recomenda-se essa transposição do Estatuto de Roma. Criar um Código Penal Internacional para os Estados Parte, diz PABLO ALFLEN, "é a melhor forma de fazer subsistir a tarefa primária dos Estados Partes de promover a persecução dos fatos puníveis mais graves contra o Direito Internacional" 55 .

Embora essas transposições, por Estados Partes, nada acrescentem efetivamente ao que consta do Estatuto de Roma, a interpretação do judiciário alemão, em casos concretos, é que poderá corrigir várias anomalias do texto de Roma, além de, por óbvio, concretizar o viés da Strafrechtswissenschaft.

9. Em considerações finais, o que se pode afirmar é que dilatado tempo será necessário para que o Tribunal Penal Internacional apare todas as arestas que se evidenciam na leitura do Estatuto de Roma, e enquanto nações hegemônicas permanecerem alheias a essa importante jurisdição internacional, pouco avanço se terá. A transposição da norma internacional para o Estado Parte contribuirá, sem dúvida, para o aperfeiçoamento da Corte que, recém, ensaia seus primeiros passos.

O cenário que traçamos, na União Europeia, na América Latina e, depois, na Iberoamérica, com as ilhas multiculturais que estão presentes num mesmo território nacional, igualmente fazem prever travessia de longo curso, para uniformização, ou melhor, harmonização de diplomas forjados na dogmática e na política criminais.

\section{REFERÊNCIAS}

ALFLEN DA SILVA, Pablo Rodrigo (Org.). Tribunal Penal Internacional - aspectos fundamentais e o novo Código Penal Internacional alemão. Porto Alegre: Sérgio Fabris, 2004.

ALVARO DE OLIVEIRA, Carlos Alberto. Do formalismo no processo civil. 2. ed. São Paulo: Saraiva, 2003.

BUSTOS RAMÍREZ, Juan. Revisión crítica de la imputabilidad a la luz de las subculturas y la siquiatría alternativa. In: MIR PUIG, Juan (Ed.). Derecho penal y sistemas sociales. Barcelona: Univ. de Barcelona, 1981. p. 191ss.

CAPEZ, Fernando. Curso de direito penal - Parte geral. 14. ed. São Paulo: Saraiva, 2010. v. 1.

CORDERO, Franco. Procedura penale. Milão: Giuffrè, 2003.

DAVID, René. Os grandes sistemas do direito contemporâneo. 4. ed. São Paulo: Martins Fones, 2002.

DIAS, Augusto Silva. Delicta in Se e Delicta Mere Prohibita - uma análise das descontinuidades do ilícito penal moderno à luz da reconstrução de uma distinção clássica. Coimbra: Coimbra Ed., 2008. 
ESER, Albin. Mental elements - Mistake of fact and mistake of law. In: CASSESE, Antonio et al. The Rome statute of the international criminal court: a commentary. New York: Oxford Un. Press, 2002. v. I. DOTTI, René Ariel. Curso de Direito Penal - Parte geral. 3. ed. São Paulo: RT, 2010.

FERRAJOLI, Luigi. Pasado y futuro del estado de derecho. In: CARBONELL, Miguel. Neoconstitucionalismo(s). Madri: Trotta, 2003. p. 13-29.

FERRAJOLI, Luigi. Legalidad civil y legalidad penal. Sobre la reserva de código en materia penal. In: $C D J P$, n. 15.

FERREIRA DE ALMEIDA, Carlos. Introdução ao direito comparado. Coimbra: Almedina, 1998.

FLETCHER, George P. Gramática del derecho penal. Buenos Aires: Hammurabi, 2008.

FLETCHER, George P. Rethinking criminal law. New York: Oxford Un. Press, 2000.

GARCIA, Basileu. Instituições de direito penal. 2. ed. São Paulo: Max Limonad, 1952. v. 1, t. 1.

GIACOMOLLI, Nereu José. Reformas (?) do processo penal considerações críticas. Rio de Janeiro: Lumen Juris, 2008.

GOMES, Luiz Flávio. Estado Constitucional de Direito e a Nova Pirâmide Jurídica. São Paulo: Ed. Premier Máxima, 2008.

GRISOLÍA, Francisco (Org.). Código penal tipo para latinoamerica - Parte general. Santiago: Ed. Jurídica de Chile, 1974.

GUARIGLIA, Fabricio. Internacionalización del derecho penal. In: ZAFFARONI, Raúl Eugenio et al. Criminalidad, evolución del derecho penal y crítica al derecho penal en la actualidad. Simposio Argentino-Alemán. Buenos Aires: Del Puerto, 2009, p. 439-444.

HASSEMER, Wienfried. Características e crises do moderno Direito Penal. In: Revista Síntese de Direito Penal e Processual Penal, ano III, n. 18, p. 144-157, fev./mar. 2003.

HENDLER, Edmundo S. La comparación de sistemas penales. Una respuesta. In: ZAFFARONI, Raúl Eugenio et al. Criminalidad, evolución del derecho penal y crítica al derecho penal en la actualidad. Simposio Argentino-Alemán. Buenos Aires: Del Puerto, 2009. p. 131-142.

HOBSBAWM, E. J.; RANGER, T. A invenção da tradições. Rio de Janeiro: Paz e Terra. 1984.

IVKOVIĆ, Sanja Kutnjak. Exploring Lay Participation. In: Legal decision-making: Lessons from Mixed Tribunals. Cornell International Law Journal, v. 40, 2007.

JESUS, Damásio E. Direito penal - Parte geral. 31. ed. São Paulo: Saraiva, 2010. v. 1.

LÓPEZ GOLDARACENA, Oscar. Cooperación con la Corte Penal Internacional - Genocídio, crímenes de guerra, crímenes de lesa humanidad. Montevidéu: Fundación de Cultura Universitária, 2008.

MATUS ACUÑA, Jean Pierre. La transformación de la teoría del delito en el derecho penal internacional. Barcelona: Atelier, 2008 .
MELENDO PARDOS, Mariano. Imputación subjetiva y error en el Estatuto de la Corte Penal Internacional - desafíos para la dogmática penal continental. Barcelona: Atelier, 2008.

OSÓRIO, Fábio Medina. Direito administrativo sancionador. São Paulo: RT, 2011.

PASTOR, Daniel R. Recodificación penal y principio de reserva de código. Buenos Aires: Ad-Hoc, 2005.

RIEFF, David. Contra la memoria. Barcelona: Debate, 2012.

ROMEO CASABONA, Carlos María (Org.). La insostenible situación del derecho penal. Granada: Comares, 2000.

RUGGIERO, Vicenzo. Delitos de los débiles de los poderosos ejercicios de anticriminología. Buenos Aires: AdHoc, 2005.

SANTOS, Juarez Cirino dos. Direito penal - Parte geral. Curitiba: Lumen Juris/ICPC, 2006.

SCARMAN, Lord Leslie. O direito inglês: a nova dimensão. Porto Alegre: Sérgio Fabris, 1978.

SCHÜNEMANN, Bernd (Org.). Proyecto alternativo de persecución penal europea. Madri: Dykinson, 2007.

SCHÜNEMANN, Bernd (org). Quaderni di diritto penale comparato internazionale. Milão: Giuffrè, 2007.

SILVA SÁNCHEZ. La expansión del derecho penal: aspectos de la política criminal en las sociedades posindustriales. Buenos Aires: BdeF, 2008.

SOUSA SANTOS, Boaventura. Nota sobre a história jurídicosocial de Pasárgada. In: SOUSA, José Gerardo (Org.). Introdução crítica ao direito. 4. ed. Brasília: Universidade de Brasília, 1993.

TIGAR, Michael E.; LEVY, MADELEINE R. $O$ direito $e$ a ascensão do capitalismo. Rio de Janeiro: Zahar, 1978.

TIMM, Luciano Benetti. "Descodificação", Constitucionalização e Reprivatização no Direito Privado - O código civil ainda é útil?" In: The Latin American and Caribbean Journal of Legal Studies, v. 3, n. 1, 2008.

TOLEDO, Francisco de Assis. Princípios básicos de direito penal. São Paulo: Saraiva, 2008.

VERVAELE, John E. A União Europeia e a harmonização da aplicação das políticas penais - um Cessio Bonorum ao terceiro pilar? In: Sistema Penal \& Violência, Porto Alegre, v. 1, n. 1, p. 66-83, jul./dez. 2009. Acesso online.

VOGLER, Richard. El sistema acusatório en los procesos penales en Inglaterra y en Europa Continental. In: WINTER, Lorena Bachmaier (Org.). Proceso penal y sistemas acusatórios. Madri: Marcial Pons, 2008.

WERLE, Gerhard. Pasado, presente y futuro del tratamiento jurídico-penal de los crimenes internacionales. Buenos Aires: Hammurabi, 2012.

ZAFFARONI, Raúl Eugenio. La pachamama y el humano. Buenos Aires: Ediciones Madres de Plaza de Mayo/Ediciones Colihue, 2012.

ZAFFARONI, Raúl Eugenio et al. Criminalidad, evolución del derecho penal y crítica al derecho penal en la acutalidad. Buenos Aires: Del Puerto, 2009.

\section{NOTAS}

1 Docente Convidado do Programa de Pós-Graduação da UFRGS. Doutor em Direito do Estado e Teoria do Direito (UFRGS). Associado ao Instituto Brasileiro de Ciências Criminais (IBCCRIM).

2 DAVID, René. Os grandes sistemas do direito contemporâneo. 4. ed. São Paulo: Martins Fontes, 2002.

3 VOGLER, Richard. El sistema acusatório en los procesos penales en Inglaterra y en Europa Continental. In: WINTER, Lorena Bachmaier
(Org.). Proceso penal y sistemas acusatórios. Madri: Marcial Pons, 2008, p. 177-194.

4 HENDLER, Edmundo S. La comparación de sistemas penales. Una respuesta. In: ZAFFARONI, Raúl Eugenio et al. Criminalidad, evolución del derecho penal y crítica al derecho penal en la actualidad. Simposio Argentino-Alemán. Buenos Aires: Del Puerto, 2009, p. 131-142.

5 FERREIRA DE ALMEIDA, Carlos. Introdução ao direito comparado. Coimbra: Almedina, 1998.

6 FERREIRA DE ALMEIDA (1998), op. cit., p. 11. 
7 FERREIRA DE ALMEIDA (1998), op. cit., p. 12.

8 HENDLER, Edmundo S. (2009), op. cit., p. 139.

${ }^{9}$ HENDLER (2009), cit., p. 140

${ }^{10}$ DAVID, René (2002), p. 351-352.

${ }^{11}$ NEREU GIACOMOLLI, fundado em FRANCO CORDERO (Procedura Penale. Milão: Giuffrè, 2003, p. 38-39), anota que "o modelo inquisitorial napoleônico não aboliu totalmente a base doutrinária do modelo sacro (Concilium Veronensis de 1184 e Concilium Maleficarum de 1215), na medida em que manteve a gestão da prova sob a iniciativa judicial (descoberta da verdade) e a instrução secreta, apesar de ter adotado a separação das funções, a oralidade e ter atribuído a defesa a um sujeito próprio. O inquisitório reformado (para uns, acusatório formal), secular ou laico amenizou a problemática do sacro inquisitório, sem romper com a essência do modelo, pois a manutenção e o fortalecimento do poder, bem como a vontade de agradar aos súditos foram as preocupações do novo modelo político." (GIACOMOLLI, Nereu José. Reformas (?) do Processo Penal - considerações críticas. Rio de Janeiro: Lumen Juris, 2008, p. 5, nota n. 1).

12 Fazemos, aqui, uma simplificação, pois em verdade, embora na Inglaterra a Magna Carta tenha sido invocada, frequentemente, em combate ao sistema judiciário puramente inquisitivo, houve longa aplicação da Inquisição, com métodos canônicos, "iniciando-se no século XV e incluindo o emprego de tortura para obrigar os suspeitos a falar." (TIGAR, Michael E.; LEVY, MADELEINE R. $O$ direito e a ascensão do capitalismo. Rio de Janeiro: Zahar Ed., 1978, p. 253). O Parlamento legalizou a inquisição, logo depois, e quando Henrique VIII aboliu a inquisição católica, elevando-se, como rei, à condição de chefe da Igreja Anglicana, sendo já chefe da justiça política, equiparou heresia e traição $\mathrm{e}$, em ambos os casos, o procedimento era plenamente inquisitivo.

${ }^{13}$ IVKOVIĆ, Sanja Kutnjak. "Exploring Lay Participation". In: Legal Decision-Making: Lessons from Mixed Tribunals. Cornell International Law Journal, v. 40, 2007, p. 434.

14 TIGAR, Michael E.; LEVY, MADELEINE (1978), p. 255.

15 TIGAR, Michael E.; LEVY, MADELEINE (1978), p. 260.

16 SANTOS, Juarez Cirino dos. Direito penal - Parte geral. Curitiba: Lumen Juris/ICPC, 2006, p. 71.

17 TOLEDO, Francisco de Assis. Princípios básicos de direito penal. São Paulo: Saraiva, 2008, p. 80. Mas é também possível uma leitura quádrupla de elementos do delito: conduta ou ação, tipo, ilícito, culpabilidade, mas esse fracionamento ignora o fato de que só interessa a ação típica - e, portanto, o mais acertado é retornar aos três elementos com frequência apontados: tipicidade, ilicitude, culpabilidade.

18 SANTOS, Juarez Cirino (2006), p. 72.

${ }^{19}$ GARCIA, Basileu. Instituições de direito penal (v. 1, t. 1). 2. ed. São Paulo: Max Limonad, 1952, p. 195.

20 DOTTI, René Ariel. Curso de direito penal - Parte geral. 3. ed. São Paulo: RT, 2010, p. 377. Na mesma obra, verbete 68, DOTTI faz acurado estudo acerca da culpabilidade. Defendem a tese do mestre paranaense, JESUS, Damásio E. Direito penal - Parte geral, v. 1, 31. ed. São Paulo: Saraiva, 2010. Em sua nota introdutória, DAMÁSIO destaca: "E culpabilidade, em função de sua natureza, não integrando as características do fato punível, não é estudada na teoria geral do crime. Abrimos para ela um título especial situado entre a doutrina do delito e a da pena." (p. 8). V. Capítulo XL e ss. Do mesmo teor o ensinamento de CAPEZ, Fernando. Curso de direito penal - Parte geral, v. 1, 14. ed. São Paulo: Saraiva, 2010, p. 134-136 e 323ss.

${ }^{21} \mathrm{O}$ autor principal do anteprojeto é ASSIS TOLEDO, razão pela qual sempre se recomenda a leitura de seus Princípios básicos de direito penal, espécie de exposição de motivos alargada.

22 Teorias como da imputação objetiva, do domínio do fato, do direito penal do inimigo, escolas funcionalistas - todos trazem as marcas de autores como CARL ROXIN, GÜNTER JAKOBS, WINFRIED HASSEMER, ALBIN ESER, BERND SCHÜNEMANN, CORNELIUS PRITTWITZ (recomenda-se leitura de amplo panorama sobre a produção jurídicopenal alemã em: (1) ROMEO CASABONA, Carlos María (Org.). La insostenible situación del derecho penal. Granada: Ed. Comares, 2000; e (2) ZAFFARONI, Eugenio Raúl et al. Criminalidad, evolución del derecho penal y critica al derecho penal en la acutalidad. Buenos Aires: Del Puerto, Hans-Jörg ALBRECHT, Ulrich SIEBER, Jan-Michael SIMON, Felix SCHWARZ - compiladores, 2009).

23 SCARMAN, Lord Leslie. $O$ direito inglês: a nova dimensão. Porto Alegre: Sérgio Fabris, 1978; FLETCHER, George P. Rethinking Criminal Law. New York: Oxford Un. Press, 2000; del derecho penal. Buenos Aires: Hammurabi, 2008.

${ }^{24}$ MATUS, Jean Pierre. La transformación de la teoría del delito en el derecho penal internacional. Barcelona: Atelier, 2008, p. 51-53.
25 MATUS (2008), 118-125.

${ }^{26}$ ESER, Albin. "Mental elements - Mistake of fact and mistake of law". In: CASSESE, Antonio et al. The Rome statute of the international criminal court: a commentary, v. I, Oxford Un. Press, 2002, p. 891ss.

27 Recklesnessé desconsideração. V. MUÑOZ CONDE/GARCÍA ARÁN, MERCEDES. Derecho penal - Parte general - 2. ed., p. 290. Espécie de ulterior critério para matizar a existência da vontade a respeito do resultado, quanto aodolo eventual. No sistema da Common Law, portanto, há recklesness, a falta de respeito ou a indiferença acerca do bem jurídico protegido (teoria do sentimento)

${ }_{28}$ MELENDO PARDOS, Mariano. Imputación subjetiva y error en el Estatuto de la Corte Penal Internacional - desafíos para la dogmática penal continental. Barcelona: Atelier, 2008, p. 30, nota 32.

${ }^{29}$ ESER (2002), apud MELENDO PARDOS (2008), p. 30.

${ }^{30}$ MELENDO PARDOS (2008), p. 31.

31 Vide, para aprofundamento deste ponto, DIAS, Augusto Silva. Delicta in Se e Delicta Mere Prohibita - uma análise das descontinuidades do ilícito penal moderno à luz da reconstrução de uma distinção clássica. Coimbra: Coimbra Ed., 2008.

32 V. RIEFF, David. Contra la memoria. Barcelona: Debate, 2012.

${ }^{33}$ HOBSBAWM, E. J.; RANGER, T. A invenção da tradições. Rio de Janeiro: Paz e Terra, 1984 (destaque para o capítulo intitulado "A produção em massa de tradições: Europa, 1870 a 1914").

34 VERVAELE, John E. "A União Europeia e a harmonização da aplicação das políticas penais - um Cessio Bonorum ao terceiro pilar? In: Sistema Penal \& Violência, Porto Alegre, v. 1, n. 1, p. 66-83, jul./dez. 2009.

35 VERVAELE (2009), p. 68.

${ }^{36}$ Sobre o Projeto Alternativo, v. Cadernos Luis Jiménez de Asúa, em espanhol (ed. Dykinson, 2007) e os Quaderni di diritto penale comparato internazionale, ed. Europeo, em italiano (Giuffrè, 2007).

37 A publicação do Projeto de código penal tipo para a América Latina foi efetivadaem 1974, pela Editorial Jurídica do Chile. É um total de 112 artigos, abrangendo desde a aplicação da lei penal no espaço e no tempo, até a extinção da ação penal e da pena (extinção da punibilidade). V. GRISOLÍA, Francisco (Org.). Código penal tipo para Latinoamerica - Parte general. Santiago: Ed. Jurídica de Chile, 1974.

${ }^{38}$ Expressão de RUDOLF POLLAK, em Sistem des Österreichischen Zivilprozessrechtes, 2. ed. Wien, Manz, 1932, p. III, apud ALVARO DE OLIVEIRA, Carlos Alberto. Do formalismo no processo civil. 2. ed. São Paulo: Saraiva, 2003, p. 75.

${ }^{39}$ BUSTOS RAMÍREZ, Juan. "Revisión crítica de la imputabilidad a la luz de las subculturas y la siquiatría alternativa. In: MIR PUIG, Juan (Ed.). Derecho penal y sistemas sociales. Barcelona: Un. de Barcelona, 1981, p. $191 \mathrm{ss}$.

40 SOUSA SANTOS, Boaventura. "Nota sobre a história jurídico-social de Pasárgada". In: SOUSA, José Gerardo (Org.). Introdução crítica ao direito. 4. ed. Brasília: Universidade de Brasília, 1993.

${ }^{41}$ ZAFFARONI, Eugenio Raúl. La pachamama y el humano. Buenos Aires: Ediciones Madres de Plaza de Mayo/Ediciones Colihue, 2012.

$42 \mathrm{O}$ relatório de vários encontros da Comissão Redatora podem ser encontrados nas seguintes publicações: I encontro - revista colombiana El Penalista e número monográfico 1 da Revista Canaria de Ciencias Penales; II encontro - dezembro 1997 da Revista Canaria de Ciencias Penales, contendo os Estatutos do Instituto Iberoamericano de Especialização em Ciências Penais (Ibero-curso, celebrado todos os meses de janeiro, nas Ilhas Canárias); III encontro - número monográfico 1 da Revista Canaria de Ciencias Penales (1999) e volume especial editado pela própria Comissão Redatora (2000), na Universidade externado da Colombia; VII encontro - livro editado pela Universidad Externado de Colombia, com o título de Derecho Penal y Sistema Acusatorio en Iberoamérica, compilado pelo secretário perpétuo da Comissão Redatora, CANCINO, Antonio José (2003).

${ }^{43}$ ANEXO I - INFORME SOBRE LOS ÚLTIMOS TRABAJOS DE LA COMISIÓN REDACTORA DEL CÓDIGO PENAL TIPO IBEROAMERICANO (2003), p. 112.

44 "Descodificação" - escreve BENETTI TIMM - "é um neologismo de decodificazione, expressão italiana criada por NATALINO IRTI [...]. A tradução literal seria decodificação, mas entendemos que a expressão descodificação represente melhor o sentido empregado por IRTI de fuga dos códigos e não dedecodificação de alguma mensagem.” TIMM, Luciano Benetti. "Descodificação", Constitucionalização e reprivatização no direito privado - O código civil ainda é útil?" In: The Latin American and Caribbean Journal of Legal Studies, v. 3, n. 1, p. 1, 2008.

45 "Caracteriza-se a era da descodificação, portanto, pela perda da característica de centralidade no sistema de fontes pelo Código Civil. A Constituição é a salvaguarda do indivíduo. As leis especiais têm seus 
próprios princípios gerais. Há uma diversidade de institutos que fogem da disciplina do Código Civil.” TIMM (2008), p. 12.

${ }^{46}$ GOMES, Luiz Flávio. Estado constitucional de direito e a nova pirâmide jurídica. São Paulo: Ed. Premier Máxima, 2008.

47 TIMM (2008), p. 27.

${ }^{48}$ PASTOR, Daniel R. Recodificación penal y principio de reserva de código. Buenos Aires: Ad-Hoc, 2005, p. 273. V. sobre o tema, (1) FERRAJOLI, Luigi. "Pasado y futuro del Estado de derecho". In: CARBONELL, Miguel. Neoconstitucionalismo(s). Madri: Trotta, 2003, p. 13-29; (2)___ . "Legalidad civil y legalidad penal. Sobre la reserva de código en materia penal". In: $C D J P$, n. 15.

49 SILVA SÁNCHEZ. La expansión del derecho penal: aspectos de la política criminal en las sociedades posindustriales. Buenos Aires: BdeF, 2008.
${ }^{50}$ OSÓRIO, Fábio Medina. Direito Administrativo Sancionador. São Paulo: RT, 2011.

${ }^{51}$ HASSEMER, Wienfried. "Características e crises do moderno direito penal”. In: Revista Sintese de Direito Penal e Processual Penal, ano III, n. 18 , p. 144-157, fev./mar. 2003.

52 RUGGIERO, Vicenzo. Delitos de los débiles de los poderosos - ejercicios de anticriminología. Buenos Aires: AdHoc, 2005.

${ }^{53}$ V. ALFLEN DA SILVA, Pablo Rodrigo (Org.). Tribunal penal internacional - aspectos fundamentais e o novo código penal internacional alemão. Porto Alegre: Sérgio Fabris, 2004.

${ }^{54}$ V. LÓPEZ GOLDARACENA, Oscar. Cooperación com la Corte Penal Internacional - genocídio, crímenes de guerra, crímenes de lesa humanidad. Montevidéu: Fundación de Cultura Universitária, 2008.

55 ALFLEN DA SILVA (2004), p. 40

Recebido em: 17/10/2013; aceito em: 17/10/2013. 